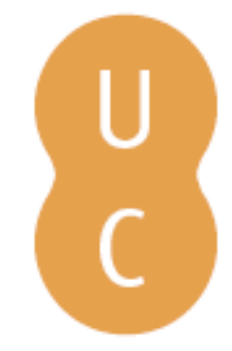

\title{
pommalina
}

\section{Avaliação de riscos ambientais no apoio ao planeamento e gestão florestal: recuperação da área ardida no baldio de Moimenta - Cabeceiras de Basto}

\author{
Autor(es): Leite, Ana \\ Publicado por: Imprensa da Universidade de Coimbra; RISCOS - Associação \\ URL \\ persistente: URI:http://hdl.handle.net/10316.2/34947 \\ DOI: $\quad$ DOI:http://dx.doi.org/10.14195/978-989-96253-3-4_147 \\ Accessed : $\quad$ 26-Apr-2023 12:11:59
}

A navegação consulta e descarregamento dos títulos inseridos nas Bibliotecas Digitais UC Digitalis, UC Pombalina e UC Impactum, pressupõem a aceitação plena e sem reservas dos Termos e Condições de Uso destas Bibliotecas Digitais, disponíveis em https://digitalis.uc.pt/pt-pt/termos.

Conforme exposto nos referidos Termos e Condições de Uso, o descarregamento de títulos de acesso restrito requer uma licença válida de autorização devendo o utilizador aceder ao(s) documento(s) a partir de um endereço de IP da instituição detentora da supramencionada licença.

Ao utilizador é apenas permitido o descarregamento para uso pessoal, pelo que o emprego do(s) título(s) descarregado(s) para outro fim, designadamente comercial, carece de autorização do respetivo autor ou editor da obra.

Na medida em que todas as obras da UC Digitalis se encontram protegidas pelo Código do Direito de Autor e Direitos Conexos e demais legislação aplicável, toda a cópia, parcial ou total, deste documento, nos casos em que é legalmente admitida, deverá conter ou fazer-se acompanhar por este aviso.

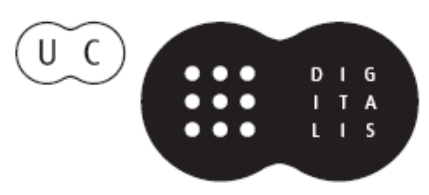



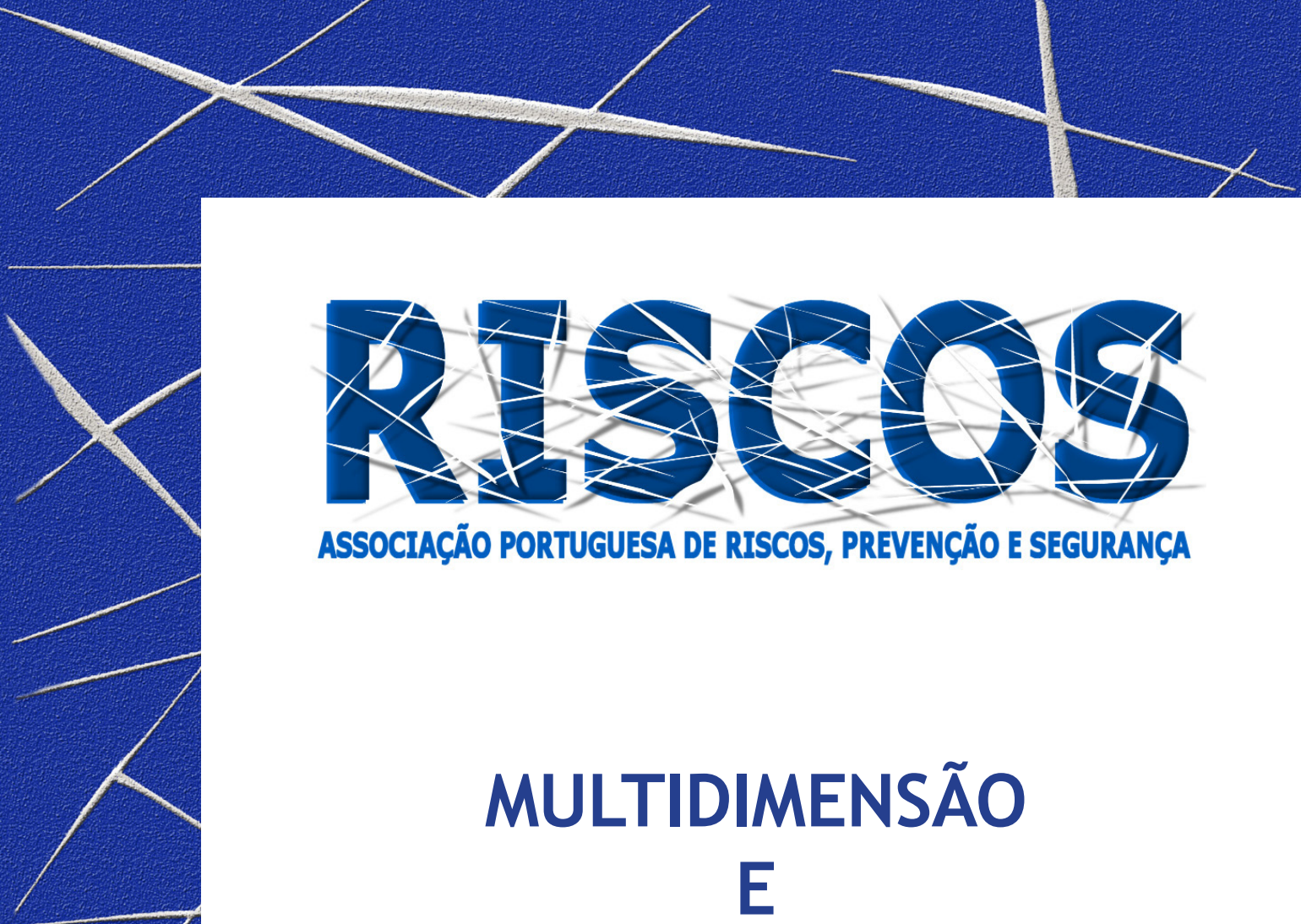

ASSOCIAÇÃO PORTUGUESA DE RISCOS, PREVENCCÃO E SEGURANÇA

MULTIDIMENSÃO

E
TERRITÓRIOS DE RISCO

III Congresso Internacional

I Simpósio Ibero-Americano

VIII Encontro Nacional de Riscos

Guimarães

2014 


\title{
AVALIAÇÃO DE RISCOS AMBIENTAIS NO APOIO AO PLANEAMENTO E GESTÃO FLORESTAL: RECUPERAÇÃO DA ÁREA ARDIDA NO BALDIO DE MOIMENTA - CABECEIRAS DE BASTO
}

\author{
Ana Leite \\ Escola Superior Agrária de Ponte de Lima - Instituto Politécnico de Viana do Castelo \\ anactleite@hotmail.com
}

\begin{abstract}
RESUMO
O presente trabalho insere-se no desenvolvimento de conhecimentos técnicos e académicos ao nível do planeamento e gestão sustentável dos espaços florestais. A investigação possui um carácter, numa primeira fase, crítico e assertivo acerca das problemáticas inerentes às alterações climáticas, às suas consequências nos espaços florestais e às medidas conhecidas para salvaguardar estes espaços; e numa segunda fase, a realização de um Plano de Gestão Florestal numa área reconhecida como terreno baldio, localizado em Moimenta Cabeceiras de Basto e cujo histórico se relaciona com inúmeros incêndios ocorridos nos últimos anos.

Para a realização do projeto final, associado a esta investigação, tornou-se necessário proceder a vários estudos que de uma forma sucinta e prática classificassem o espaço em relação à sua perigosidade de ocorrência de incêndio, de movimentação de vertentes e erosão hídrica, utilizando os sistemas de informação geográfica como ferramentas de trabalho. Os produtos finais caracterizados pelas cartas de risco de incêndio florestal, risco de movimentação de vertentes e risco de erosão hídrica permitem assim tirar conclusões acerca da perigosidade da área em várias vertentes práticas e fazer escolhas mais assertadas para medidas que podem vir a ser implementadas no espaço.

Os principais resultados indicam a possibilidade de serem implementadas medidas eficientes e atividades diferenciadas numa área tão diminuta, como é o caso. No espaço em estudo, que possui na sua totalidade 131,44 hectares, seria possível aplicar a promoção de atividades lúdicas, rentáveis para o Estado e que salvaguardem as áreas florestais de fenómenos naturais nefastos.

No final da investigação compreende-se que seria imprescindível que o Estado, enquanto entidade responsável, tivesse a gestão e o planeamento florestal como uma prioridade, dentro das suas ações governamentais, implementando atividades concretas que salvaguardassem a floresta e promovessem a biodiversidade.
\end{abstract}

Palavras-chave: alterações climáticas, ação antrópica, fenómenos naturais, planos organizacionais, ordenamento do território.

\section{Introdução}

0 presente trabalho tem o seu âmbito investigacional a gestão e planeamento de espaços florestais, considerando por um lado, uma organização bibliográfica que aborda várias temáticas integrantes e por outro lado, o caso concreto do terreno baldio de Moimenta, localizado na freguesia de Cavez, pertencente ao concelho de Cabeceiras de Basto e trata-se de uma área ardida, cuja recuperação está dependente das ações da entidade estatal responsável, o Instituto da Conservação da Natureza e das Florestas (ICNF).

Assim, com o objetivo primordial da investigação em realizar um Plano de Gestão Florestal para a área em estudo, foram analisados três tipos riscos associados a fenómenos naturais: risco de incêndio, o risco de movimento de vertentes e o risco de erosão hídrica.

\section{Riscos Ambientais no Planeamento e Gestão Florestal}

As alterações climáticas e os fenómenos associados têm provocado, ao longo dos anos, degradações constantes no meio ambiente, tendo consequências notórias na diminuição da 
qualidade de vida do ser Humano, nomeadamente na saúde, bem-estar social e na geração de riqueza. Por essa razão, torna-se crucial proteger os ecossistemas agro - florestais, trabalhando em prol do meio ambiente diminuindo assim, os efeitos das alterações climáticas no planeta e salvaguardando a saúde do ser Humano (Monbiot, 2007).

A nível europeu conhecem-se várias medidas e inúmeras associações não-governamentais que têm como principais objetivos a proteção da floresta e a promoção ativa de biodiversidade. Portugal, não sendo indiferente a todas as alterações que se fazem sentir, também está aliado a muitas dessas atividades, no entanto verifica-se a existência de algumas lacunas na gestão dos espaços florestais, sendo assim importante que haja uma maior consciencialização por parte dos principais atores na salvaguarda da floresta, não só pela sua importância ambiental mas também pela posição que este sector ocupa no mercado nacional.

O Deputado Abel Baptista, vice - presidente da Comissão de Agricultura e Mar, do Ministério da Agricultura, do Mar, do Ambiente e do Ordenamento do Território, referiu ao investigador que "a floresta portuguesa ocupa 38\% do território nacional, com 3,45 milhões de hectares e é a $12^{\text {a }}$ maior área florestal da União Europeia, sendo que $23 \%$ desta área é protegida”. Se, por um lado, se considera uma mais-valia para o país que as áreas florestais nacionais sejam tão valorizadas, por outro seria imprescindível que a gestão e o planeamento destes espaços estivessem à altura desta valoração. Não obstante à legislação que já existe e que é utilizada na gestão dos espaços florestais, o investigador reconhece que alguma desta legislação pode ser considerada como desatualizada para o que é a realidade a nível florestal. Para tal torna-se necessário uma atualização de algumas medidas e a promoção da aplicação de medidas diferenciadas que beneficiariam a área florestal nacional.

\section{Metodologia e Resultados}

Para realizar o Plano de Gestão Florestal realizaram-se alguns estudos com intuito de obter a avaliação do terreno acerca de alguns fenómenos naturais.

\section{Avaliação do Risco de Incêndio Florestal}

A avaliação do Risco de Incêndio Florestal foi realizada através de uma metodologia criada pela Autoridade Florestal Nacional em 2012, onde o estudo é feito através do cruzamento de quatro pressupostos principais: Probabilidade, Suscetibilidade, Vulnerabilidade e Valor Economico. Desta forma, foi possível concluir que no terreno em estudo, apesar da perigosidade associada aos incêndios ser elevada, pelo histórico associado, o risco de incêndio é praticamente inexistente, como se verifica na figura 1. 


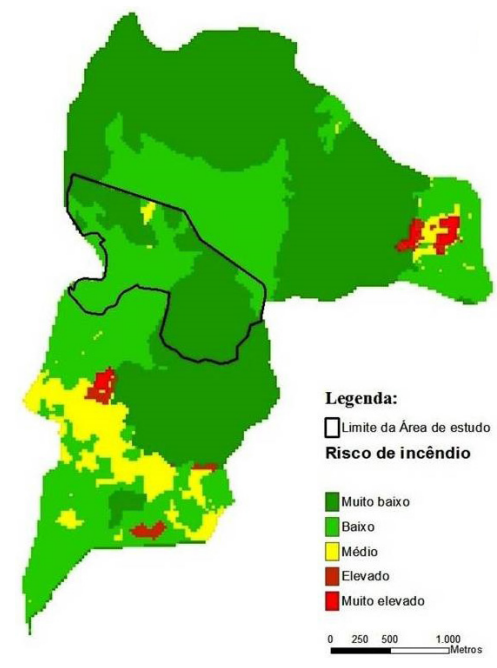

Figura 1 - Carta final de risco de incêndio florestal

\section{Avaliação do Risco de Movimentação de Massas}

A avaliação do Risco de Movimentação de Massas teve como pressuposto a metodologia de Dan Balteanu, Viorel Chedes, Mihaela Sima e Petru Enciu. Nesta metodologia os principais pressupostos ponderados foram: a precipitação média mensal da estação meteorológica de Cavez, a litologia, a sismicidade, a topografia do terreno e a suscetibilidade de ocorrência do fenómeno, tendo em conta a carta de ocupação e uso do solo. Como resultado, apresenta-se uma área onde o risco de movimentação de vertentes é parcialmente elevado, como está ilustrado na figura 2.

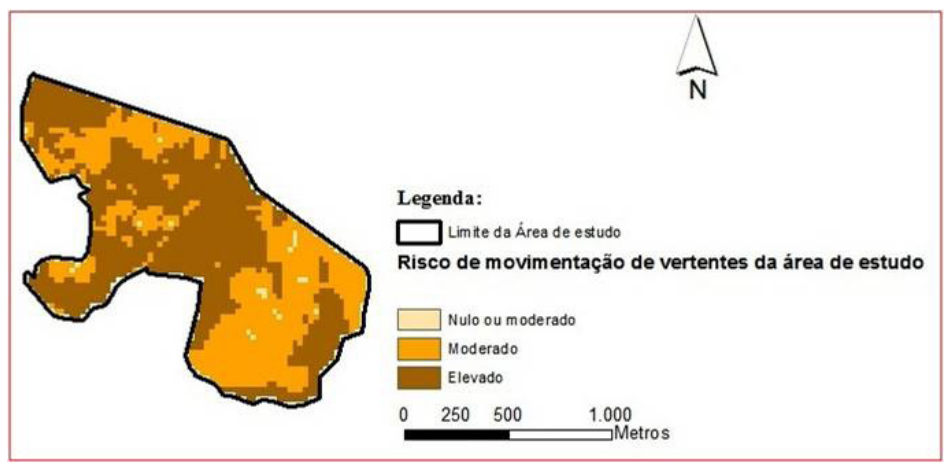

Figura 2: Carta final do risco de movimentação de massas.

\section{Avaliação do Risco de Erosão Hídrica}

Para a obtenção do estudo acerca da probabilidade de ocorrência de erosões hídricas no terreno em estudo, adaptou-se a metodologia de Wischmeier \& Smith (1995), a partir da Equação Universal de Perdas de Solo (USLE): 
$A=R \times K \times L S \times C \times P$

Nesta metodologia, os pressupostos assumidos foram as variáveis da equação de USLE:

$\mathrm{R}$ - Agressividade climática

$\mathrm{K}$ - Erodibilidade do solo

LS - Topografia do terreno

C - Coberto vegetal

P - Práticas de conservação do solo

Após consideração dos pressupostos e respetivos cruzamentos de dados foi possível conhecer a carta final de risco de erosão hídrica onde se pode considerar como muito reduzido, tal como se verifica na figura $n^{\circ} 3$.

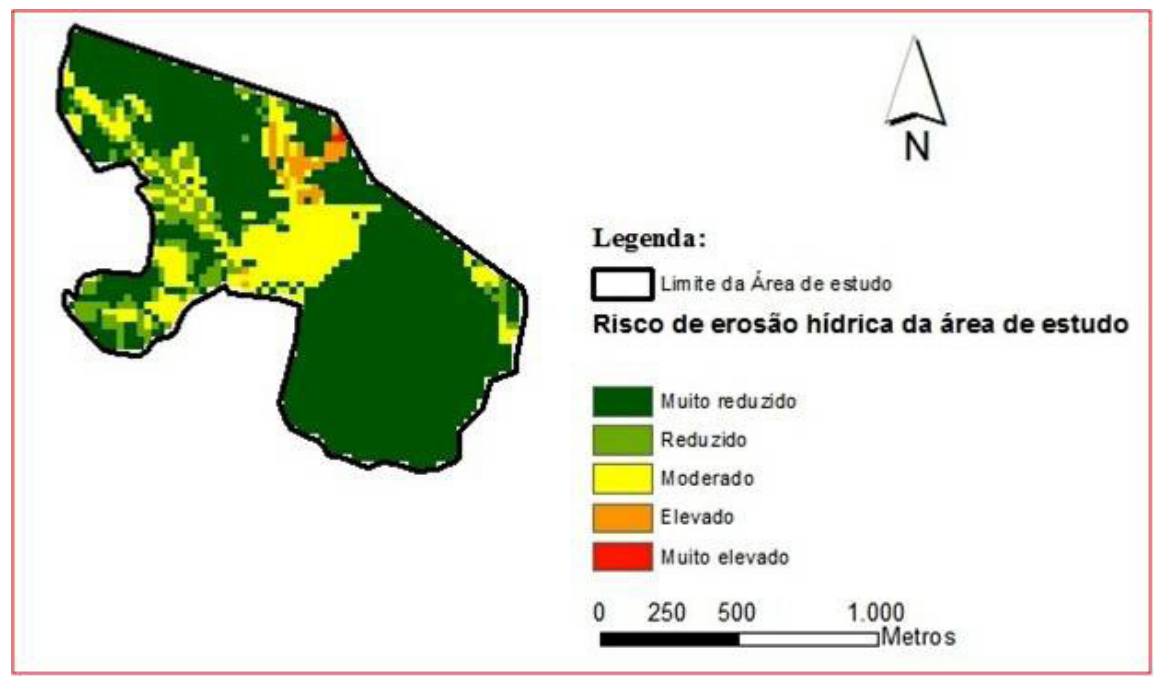

Figura $\mathrm{n}^{\circ}$ 3: Carta final do risco de erosão hídrica.

\section{Plano de Gestão Florestal}

Após todos os estudos individuais dos riscos ambientais associados, realizou-se um plano de gestão florestal, tendo em atenção a suscetibilidade da área de estudo face a ocorrência dos fenómenos estudados e às valorações que lhe foram aplicadas.

O plano de gestão florestal visa obter um conjunto de medidas a aplicar num prazo de três anos. Estas medidas têm como objetivo um planeamento florestal dinâmico, promovendo a salvaguarda da floresta atendendo à biodiversidade da flora e da fauna, e promover atividades rentáveis, mobilizando a economia nacional e impulsionando a empregabilidade.

$\mathrm{Na}$ figura $\mathrm{n}^{\circ} 4$ é ilustrado o plano de gestão florestal criado, fazendo referencia às atividades propostas. 


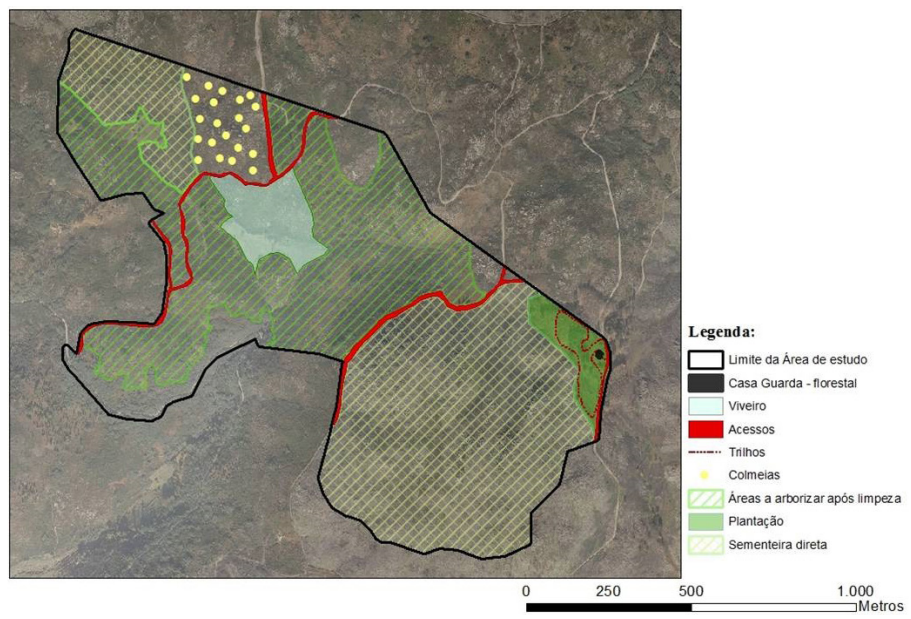

Figura $n^{\circ}$ 4: Plano de Gestão Florestal.

Assim, todas as medidas implementadas surgem, principalmente, baseadas no uso múltiplo da floresta:

1. Limpeza dos espaços - Limpeza realizada em parceria entre o ICNF e a CMCB pelo facto de se verificar que existem espécies invasoras e matos.

2. Criação e manutenção dos acessos - Medida implementada pela CMCB e surge da necessidade de criar melhores acessos para carros dos bombeiros.

3. Arborização - A arborização pretende-se que seja realizada em parceria entre o ICNF e a CMCB e tem como principais espécies arbóreas: Pinus sp., Quercus sp., Castanea sativa, Prunus avium, Laurus nobilis e Acer pseudoplatanus.

4. Implementação de um viveiro - Nesta medida pretende-se produzir espécies para uso no espaço e para venda. 0 viveiro estaria, assim, ao encargo da CMCB.

5. Iniciação à atividade apícola - Atividade crucial por possuir rentabilidade económica. As colmeias seriam geridas pelas organizações de produtores de mel da região.

6. Recuperação da casa do guarda-florestal e criação de um trilho pedestre - onde a CMCB poderia promover atividades de turismo rural.

\section{Conclusão}

Com a presente investigação pretendeu-se ter postura critica e assertiva acerca da gestão e planeamento florestal a nível nacional, e desta forma, mostrar soluções para a floresta desenvolvendo um plano de gestão florestal.

Assim, é possível concluir que até numa pequena área é possível implementar diversas medidas que respondam a uma gestão sustentável dos espaços florestais, sendo somente necessário fazer remodelações na legislação existente, onde deveria estar implícito a obrigação das entidades e dos privados a aplicação do uso múltiplo da floresta, independentemente da natureza e da escala associada a qualquer área de trabalho.

\section{Bibliografia}

Monbiot, G., 2007. Calor, como impedir o planeta arder. Via Óptima, 292 pp. 